\title{
A new $\mathrm{Ng}$ azacryptand 'Beer Can' receptor for complexation of alkali metal and $\mathrm{Pb}$ (II) cations
}

\section{Introduction}

Cryptands are a class of cage-like polycylic host molecules which were first synthesised during the 1960s and played a central historical role in the advent of supramolecular chemistry. ${ }^{1}$ The early cryptand ligands were shown to be capable of binding spherical alkali metal and alkaline earth metal cations ${ }^{2,3}$ with unprecedented thermodynamic and kinetic stabilities, and with unrivalled selectivities for complementary cationic guests. The special complexation properties of cryptand ligands, collectively termed the 'cryptate effect' are elegantly exemplified by Lehn's prototypical diazapolyoxa cryptand $222,4,5$ which is able to bind potassium cations ${ }^{6}$ selectively over sodium and rubidium, 7,8 with stability constants which are several orders of magnitude greater than those observed for macrocyclic ligands such as crown ethers and the naturally occurring antibiotic valinomycin, ${ }^{9}$ and with an unusually slow kinetic rate of dissociation. ${ }^{10}$ The high thermodynamic stability of metal cryptate complexes is enthalpic in origin, arising predominately from the high degree of preorganisation and low degree of solvation of the cryptand ligands; ${ }^{11}$ the ligands' stringent selectivity preferences have often been attributed to size complementarity consideration ${ }^{12}$ but other factors such as ligand flexibility and the solvation enthalpy and coordination preferences of the guest are also recognised to have an important influence. ${ }^{13-15}$

Since the early work on metal cryptate complexes, numerous cryptand host systems have been developed for metal cations, as well as anions ${ }^{16,17}$ and organic guest molecules. ${ }^{18}$ The resulting cryptate systems have found varied applications, for example as phase transfer catalysts, ${ }^{19}$ anion-exchange column stationary phases, ${ }^{20}$ ionophores in ion-selective electrodes, ${ }^{21-23}$ inert cations for the stabilisation of unusual alkalide ${ }^{24,25}$, electride ${ }^{26}$ and homopolyatomic ${ }^{27-29}$ anions, and components of higher order rotaxane-based molecular muscles. ${ }^{30}$ Cryptands have also attracted interest as selective chelates for the detection and sequestration of toxic heavy metal cations such as $\mathrm{Pb}(\mathrm{II})$, which is a pernicious environmental pollutant as a consequence of the historical widespread industrial use of lead in the production of lead-acid batteries; paints, pigments and glazes; ammunitions; plumbing pipes, solder and fixtures; herbal medicines; and leaded fuels. Once ingested or inhaled by humans lead is known to accumulate in soft tissues including the liver, kidneys and brain, where it can bind to the phosphate, thiol and amide groups of nucleic acids, ${ }^{31}$ proteins ${ }^{32}$ and enzymes ${ }^{33}$ with severe toxicological effects, especially in young children. ${ }^{34}$ Efforts to control the industrial use of this toxic metal have led to declining levels of lead in the environment, food and the human blood stream over recent decades; however there is thought to be no safe exposure threshold, with even low exposure levels presenting a significant public health risk. ${ }^{35}$ Selective chelate forming compounds which can be used for the environmental detection and extraction of lead, as well as in the diagnosis and treatment of lead intoxication, are therefore highly attractive targets. ${ }^{36,37}$

Herein we report the convenient one-pot synthesis of a new nonaazacryptand ligand which is shown to encapsulate alkali metal and divalent lead cations. The sodium, potassium and lead complexes of the cryptand ligand are characterised in solution and in the solid state. Preliminary cation binding competition experiments indicate that the cryptand exclusively complexes $\mathrm{Pb}(\mathrm{II})$ and $\mathrm{Na}^{+}$in the presence of $\mathrm{Ca}^{2+}, \mathrm{Zn}(\mathrm{II})$ and $\mathrm{K}^{+}$cations in methanol solution.

\section{Results and Discussion}

The new cryptand ligand comprises two triazacyclononane (TACN) capping groups which are bridged by three pyridyl side-arms to form a rigid cage-like structure in which each of the nine nitrogen donor groups converges towards a central cation binding cavity. The cryptand was synthesised via a one-pot [2+3] condensation reaction between TACN and 2,6-bis(bromo)methyl pyridine in the presence of $\mathrm{M}_{2} \mathrm{CO}_{3}(\mathrm{M}=\mathrm{Na}, \mathrm{K})$ in refluxing acetonitrile. Purification by column chromatography on neutral alumina followed by counteranion exchange using Amberlite ion-exchange resin afforded the alkali metal cryptate products as their chloride salts (Scheme 1). 


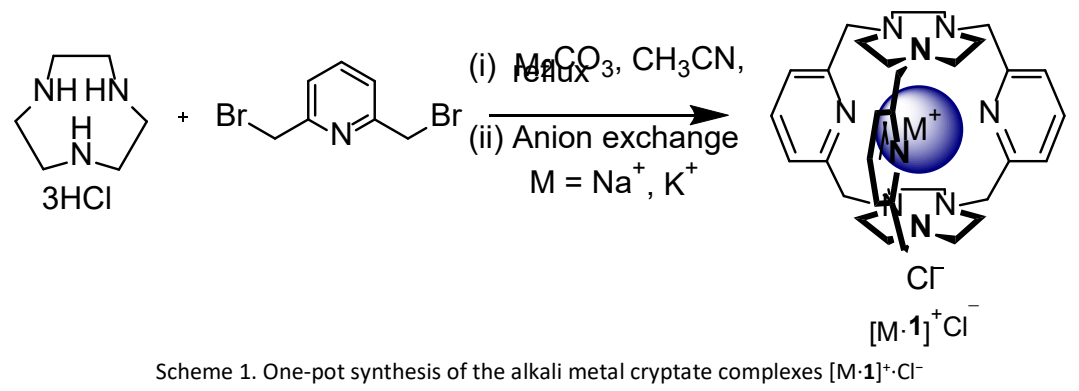

For the reaction performed in the presence of $\mathrm{K}_{2} \mathrm{CO}_{3}$ a single product was isolated in $20 \%$ yield. The electrospray mass spectrum of this compound showed a single peak at $\mathrm{m} / \mathrm{z}=606.34$, corresponding to the $[\mathrm{M}-\mathrm{Cl}]^{+}$ion for the potassium cryptate $[\mathrm{K} \cdot \mathbf{1}]^{+} \cdot \mathrm{Cl}^{-}$. The ${ }^{1} \mathrm{H}$ NMR spectrum of this species in $\mathrm{CD}_{3} \mathrm{OD}$ (Figure 1 ) reveals diastereoptopic splitting of the methylene proton signals $\mathrm{H}_{3}$ and $\mathrm{H}_{3}$, along with the appearance of four separate signals corresponding to the ethylene protons $\mathrm{H}_{4}, \mathrm{H}_{4}{ }^{\prime}, \mathrm{H}_{5}$ and $\mathrm{H}_{5}{ }^{\prime}$, consistent with a helical cryptate structure with overall $C_{3}$ point group symmetry. Variable temperature ${ }^{1} \mathrm{H} N M R$ experiments in DMSO- $\mathrm{d}_{6}$ revealed that coalescence of the diastereotopic methylene signals is not observed below $120^{\circ} \mathrm{C}$, suggesting a high kinetic barrier to conformational interconversion. CHECK THIS AGAIN. There is no ${ }^{1} \mathrm{H}$ NMR evidence of any additional asymmetry between the two TACN capping groups or the three pyridyl side-arms, which is consistent with an endo binding mode in which the potassium cation resides centrally within the cryptand's cavity.

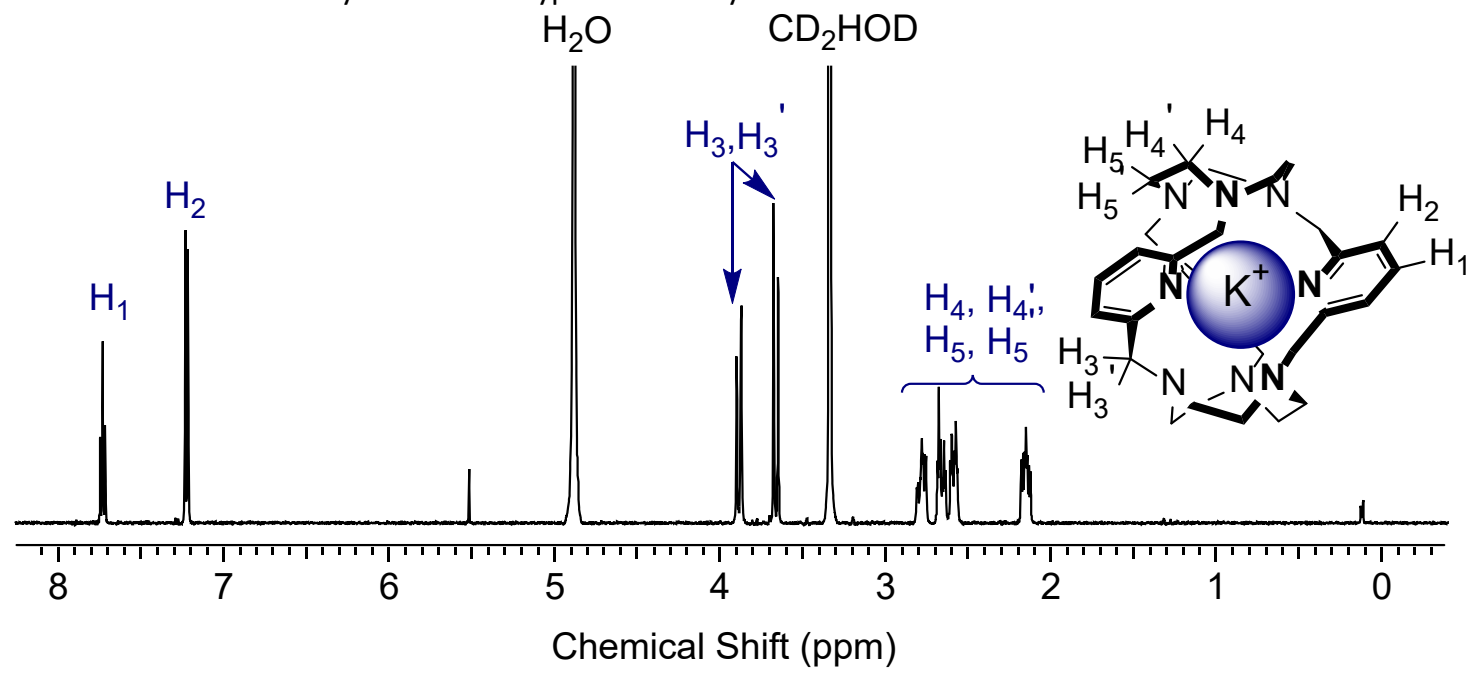

Figure $1 .{ }^{1} \mathrm{H}$ NMR spectrum $\left(400 \mathrm{MHz} ; \mathrm{CD}_{3} \mathrm{OD} ; 298 \mathrm{~K}\right)$ of the potassium cryptate complex $[\mathrm{K} \cdot 1]^{+} \mathrm{Cl}^{-}$

In contrast, for the sodium templated reaction the formation of two separate products was apparent from analysis of the crude ${ }^{1} \mathrm{H}$ NMR spectrum and after chromatographic purification each of these products were isolated in yields of $27 \%$ and $8 \%$ respectively. While both products were observed to fly as $[\mathbf{1}+\mathrm{Na}]^{+}$and $[\mathbf{1}+\mathrm{Na}]^{2+}$ by electrospray mass spectrometry, the two compounds are clearly distinguishable by differences in their ${ }^{1} \mathrm{H}$ NMR spectra. The spectrum of the minor product is analogous to that of the product of the potassium-templated reaction, suggesting a helical sodium cryptate structure, $[\mathrm{Na} \cdot \mathbf{1}]^{+} \cdot \mathrm{Cl}^{-}$, in which the cation is centrally located within the cavity (Figure 2). The ${ }^{1} \mathrm{H}$ NMR spectrum of the major product reveals additional asymmetry between the top and bottom of the molecule, within the methylene and ethylene protons appearing as four and eight separate signals respectively. Furthermore an extra proton signal is observed at $10.2 \mathrm{ppm}$ with an integral value of 1. The 2-D COSY spectrum revealed through-bond coupling interactions between this proton and the ethylene and methylene protons, suggesting that the extra signal appears as a result of internal protonation of one of the bridgehead nitrogen atoms (Figure 2). This bridgehead nitrogen proton signal is consistently observed as a sharp singlet in the protic $\mathrm{CD}_{3} \mathrm{OD}$ solvent, from which it is apparent that the rate of the hydrogen-deuterium exchange reaction is slower than the timescale of the NMR experiment. Kinetically slow proton transfer rates are a characteristic feature of azacryptand ligands which is thought to reflect the restricted conformational dynamics of these cage-like structures. ${ }^{38,39}$ The major product was therefore assigned as the protonated sodium cryptate $[\mathrm{Na} \cdot \mathrm{H} \cdot \mathbf{1}]^{2+} \cdot 2 \mathrm{Cl}^{-}$. The sodium cation presumably does not interact with the protonated TACN group and is instead displaced from the centre of the cryptand cavity towards the neutral TACN group, forming a six-coordinate complex with the three nitrogen atoms of this non-protonated TACN group and the three pyridyl nitrogen atoms. The ready protonation of the sodium cryptate structure presents a possible indication that the size and topology of the ligand's cavity does not constitute 
an optimal coordination environment for the sodium cation, which may prefer a lower coordination number and shorter $\mathrm{Na}^{+}-\mathrm{N}_{\text {TACN }}$ distances than can be achieved in the symmetrical nonacoordinate complex.‡

(i)

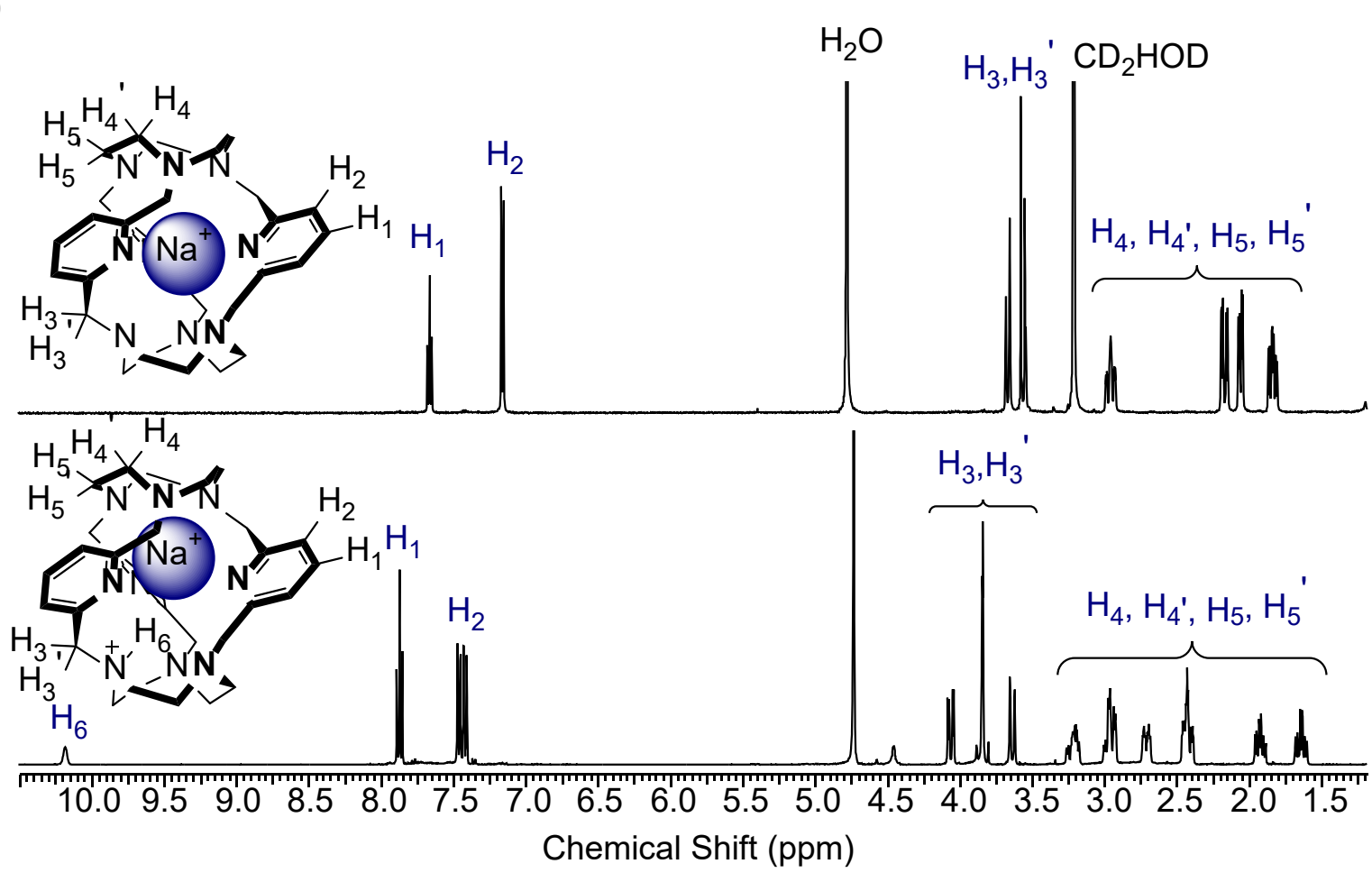

(ii)

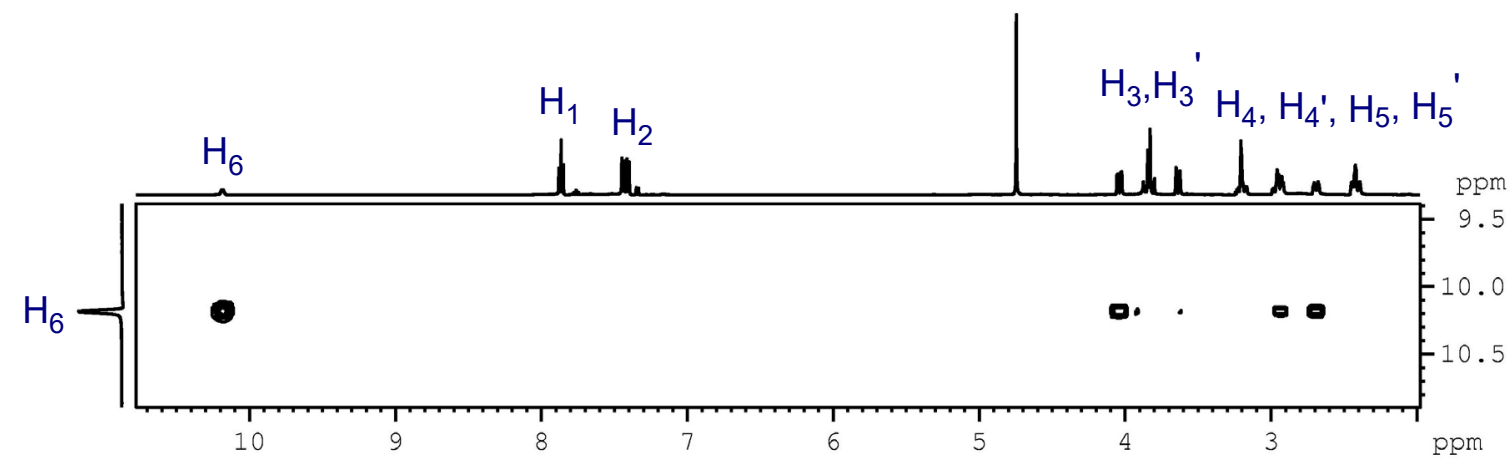

Figure 2. ${ }^{1} \mathrm{H}$ NMR characterisation $\left(400 \mathrm{MHz} ; \mathrm{CD}_{3} \mathrm{OD} ; 298 \mathrm{~K} \text { ) of the sodium cryptate complexes: (i) comparative 1-D spectra of the symmetrical complex [ } \mathrm{Na} \cdot 1\right]^{+} \mathrm{Cl}{ }^{-}$ (top) and monoprotonated complex $[\mathrm{Na} \cdot \mathrm{H} \cdot \mathbf{1}]^{+} 2 \mathrm{Cl}^{-}$(bottom) and (ii) section of the 2-D COSY spectrum of the monoprotonated complex $[\mathrm{Na} \cdot \mathrm{H} \cdot \mathbf{1}]^{+} 2 \mathrm{Cl}^{-}$.

\section{Solid state characterisation of alkali metal cryptate complexes}

The complexes $[\mathrm{K} \cdot \mathbf{1}]^{+} \cdot \mathrm{PF}_{6}^{-}, \S[\mathrm{Na} \cdot \mathbf{1}]^{+} \cdot \mathrm{Cl}^{-}$and $[\mathrm{Na} \cdot \mathrm{H} \cdot \mathbf{1}]^{2+} \cdot 2 \mathrm{Cl}^{-}$were characterised by $\mathrm{X}$-ray crystallography in the solid state and their structures compared with that of the diprotonated free ligand, $\left[\mathrm{H}_{2} \cdot \mathbf{1}\right]^{2+} \cdot 2 \mathrm{Br}^{-} \cdot$.

Diprotonated free ligand. The solid state structure of the diprotonated free ligand $\left[\mathrm{H}_{2} \cdot \mathbf{1}\right]^{2+} \cdot 2 \mathrm{Br}^{-}($Figure 3 ) confirms that the ligand skeleton adopts a $C_{3}$ symmetric helical conformation, as suggested by the solution ${ }^{1} \mathrm{H}$ NMR spectra of the cryptate complexes $[\mathrm{K} \cdot \mathbf{1}]^{+} \cdot \mathrm{Cl}^{-}$and $[\mathrm{Na} \cdot \mathbf{1}]^{+} \cdot \mathrm{Cl}^{-}$. The two TACN capping groups are staggered with respect to each other and the pyridyl side-arms are twisted by $45-49^{\circ}$ in the same sense with respect to the planes defined by the three nitrogen atoms in each TACN capping group. Despite possessing this conformational chirality, the ligand crystallised as a racemate in the monoclinic non-chiral space group $P 2_{1} / c$. All of the nitrogen atoms adopt an endo conformation with their lone pairs converging towards the spheroidal cryptand cavity. A proton can be seen to reside on one of the bridgehead nitrogen atoms in each TACN capping group. The two bromide counteranions are 
presumably too large to penetrate the cavity and are instead located externally, where they participate in a series of $\mathrm{C}-\mathrm{H}-\mathrm{Br}^{-}$short contacts with the $\mathrm{CH}_{2}$ groups of the cryptand ligand and the dichloromethane solvent molecules.
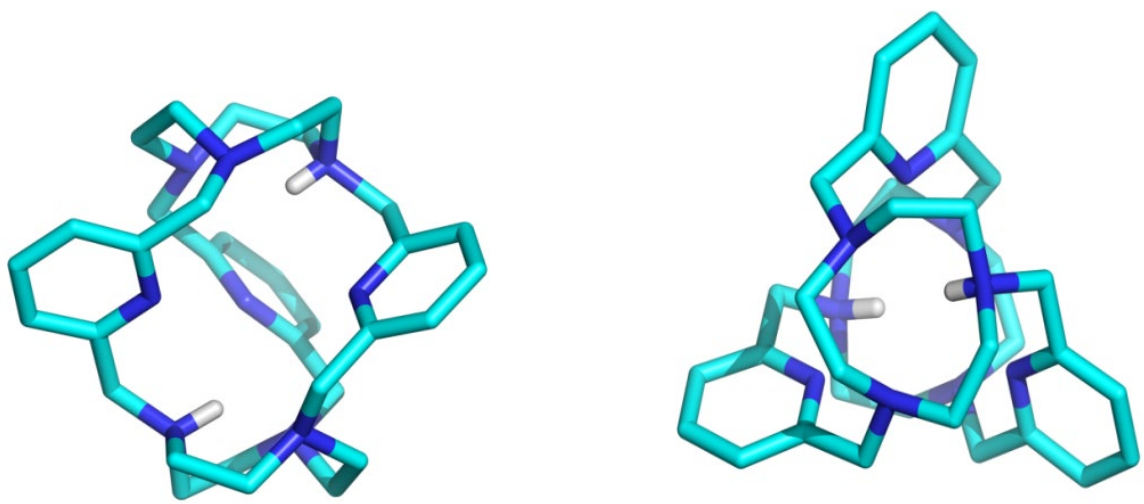

Figure 3. Orthogonal views of the solid state structure of the diprotonated free ligand $\left[\mathrm{H}_{2} \cdot \mathbf{1}\right]^{2+} \cdot 2 \mathrm{Br}^{-}$. For clarity, solvent molecules, non-polar hydrogen atoms and the two bromide counteranions have been omitted.

$[\mathrm{Na} \cdot \mathbf{1}]^{+} \cdot \mathrm{Cl}^{-}$. The cryptate complex $[\mathrm{Na} \cdot 1]^{+} \cdot \mathrm{Cl}^{-}$was similarly observed to crystallise as a racemate in the centrosymmetric space group $P \overline{1}$. The asymmetric unit contains two sodium cryptate complexes which are structurally almost identical. In each complex the sodium cation is centrally located within the cryptand cavity (Figure 4), lying in the plane defined by the three pyridyl nitrogen atoms and intersecting the $C_{3}$ axis which connects the centroids of the three nitrogen atoms in each TACN capping group ( $\angle$ centroid-Na+-centroid: $179.4^{\circ}$ and $\left.179.7^{\circ}\right)$. This allows the each cation to interact with the nine available nitrogen donor atoms in a distorted tricapped trigonal prismatic geometry. The $\mathrm{Na}^{+}-\mathrm{N}_{\text {TACN }}$ distances fall in the range $2.82-2.87 \AA$ ( $m e a n=2.840 \AA$ ) and are comparable to the sum of the van der Waals and ionic radii for nitrogen and nonacoordinate $\mathrm{Na}^{+}(2.79 \AA \AA) .40,41$, whereas shorter and $\mathrm{Na}^{+}-\mathrm{N}_{\mathrm{py}}$ distances of $2.577-2.611 \AA$ (mean $=2.590 \AA$ ) are observed. In comparison to the diprotonated free ligand, the cryptand ligand is contracted along the $C_{3}$ axis and expanded in the perpendicular plane in order to optimally accommodate the sodium cation: this can be seen from the smaller TACN centroid-tocentroid distances (4.537 $\AA$ and $4.564 \AA$ ), greater $\mathrm{N}_{p y}-\mathrm{N}_{p y}$ distances (4.507-4.477 $\AA$; mean = 4.485 $\mathrm{A}$ ) and increased TACN NCCN torsion angles $\left(49.7-52.0^{\circ}\right.$; mean $\left.=51.0^{\circ}\right)$ compared to those observed in the structure of $\left[\mathrm{H}_{2} \cdot \mathbf{1}\right]^{+} \cdot 2 \mathrm{Br}^{-}$ (Figure 5 and Table 1).

$[\mathrm{Na} \cdot \mathbf{H} \cdot \mathbf{1}]^{2+} \cdot \mathbf{2} \mathrm{Cl}^{-}$. The protonated sodium complex $[\mathrm{Na} \cdot \mathrm{H} \cdot \mathbf{1}]^{2+} \cdot 2 \mathrm{Cl}^{-}$crystallised in the space group Fdd2. The asymmetric unit contains one cryptate complex in which the sodium cation is significantly displaced from the centre of the cryptand cavity towards one of the two TACN groups, residing $0.58 \AA$ above the plane described by the three pyridyl nitrogen atoms (Figure 4). The cation's coordination environment can be regarded as an irregular sixcoordinate polyhedron comprising the three $\mathrm{N}_{\text {py }}$ donors $\left(\mathrm{Na}^{+}-\mathrm{N}_{\text {py }}\right.$ distances $2.465-2.550 \AA$; mean $=2.51 \AA$ ) and the three nitrogen donors from the more proximal of the two TACN groups ( $\mathrm{Na}^{+}-\mathrm{N}_{\text {TACN }}$ distances $2.475-2.483 \AA$; mean $=2.478 \AA$ ). The three shorter $\mathrm{Na}^{+}-\mathrm{N}_{\text {TACN }}$ are noticeably shorter than the $\mathrm{Na}^{+}-\mathrm{N}_{\text {TACN }}$ distances observed in the complex $[\mathrm{Na} \cdot \mathbf{1}]^{+} \cdot \mathrm{Cl}^{-}$, while the three $\mathrm{Na}^{+}-\mathrm{N}_{\mathrm{py}}$ distances are roughly comparable. The longer $\mathrm{Na}^{+}-\mathrm{N}_{\text {TACN }}$ distances $(3.404-3.518 \AA$; mean $=3.475 \AA$ ) are significantly beyond the sum of the van der Waals and ionic radii for nitrogen and six-coordinate sodium $(2.57 \AA),{ }^{40,41}$ suggesting that the more distant TACN group does not participate in any coordinative interactions with the sodium cation. The presence of a proton on one of the pivotal nitrogen atoms in this TACN group could not be unequivocally confirmed from the crystallographic data; however, the asymmetric location of the $\mathrm{Na}^{+}$cation is fully consistent with the protonated structure $[\mathrm{Na} \cdot \mathrm{H} \cdot \mathbf{1}]^{2+} \cdot 2 \mathrm{Cl}^{-}$which was assigned from the solution NMR data. In addition, the presence of electron density corresponding to a hydrogenbonding network of two chloride counteranions, disordered over three sites, and four water molecules in the solid state structure provides indirect evidence of $N$ protonation of the ligand on the basis of charge balance considerations. Since the bridgehead nitrogen proton could not be observed in the difference maps it was modelled with $33 \%$ occupancy on each of nitrogen atoms of the TACN group which is more distant from the sodium cation.

$[\mathrm{K} \cdot \mathbf{1}]^{+} \cdot \mathrm{PF}_{6}{ }^{-}$. The cryptate $[\mathrm{K} \cdot \mathbf{1}]^{+} \mathrm{PF}_{6}{ }^{-}$crystallised in the monoclinic space group $P 2_{1} / c$ and the asymmetric unit contains two crystallographically independent potassium cryptate complexes which have inverted helicities but otherwise appear to show minimal structural variations. Measurements have been taken from just one of the two complexes, since the other was found to incorporate significantly more disorder. Probably change. In agreement 
with the ${ }^{1} \mathrm{H}$ NMR assignment of this potassium cryptate, the cation is centrally located within the cavity, residing $0.02 \AA$ above the plane of the three $N_{p y}$ nitrogen donor atoms and forming an almost linear $178^{\circ}$ angle with the centroids of the two TACN groups (Figure 4). The cation can be seen to interact with the full complement of nine nitrogen donor atoms in a distorted tricapped trigonal prismatic coordination geometry, analogous to that observed in the structure of the sodium complex $[\mathrm{Na} \cdot 1]^{+} \cdot \mathrm{Cl}^{-}$. The $\mathrm{K}^{+}-\mathrm{N}_{\text {TACN }}$ distances $(2.888-2.939 \AA$; mean $=2.903 \AA$ ) and $\mathrm{K}^{+}-\mathrm{N}_{\mathrm{py}}$ distances $(2.709-2.753 \AA$; mean $=2.736 \AA$ ) are $5-13 \%$ smaller than the sum of the ionic and van der Waals radii of nine-coordinate potassium and nitrogen (3.10 $\AA$ ). ${ }^{40,41}$ Assuming that the enthalpic gain is maximised when the cation-donor atom distances are approximately equal to the sum of their ionic and van der Waals radii, the short $\mathrm{K}^{+}-\mathrm{N}_{\mathrm{py}}$ distances suggest that the volume of the cryptand's cavity may be slightly too small to accommodate the $\mathrm{K}^{+}$cation without some unfavourable overlap of electron clouds. The $\mathrm{N}_{\mathrm{py}}-\mathrm{N}_{\mathrm{py}}$ distances $(4.677-4.79 \AA$; mean $=4.737 \AA$ ) and $\mathrm{NCCN}$ torsion angles $\left(51.6-55.8^{\circ}\right.$; mean $\left.=54.8^{\circ}\right)$ are larger than those observed in the structures of both the diprotonated free ligand $\left[\mathrm{H}_{2} \cdot 1\right]^{+} \cdot 2 \mathrm{Br}^{-}$, and sodium complex $[\mathrm{Na} \cdot 1]^{+} \cdot \mathrm{Cl}^{-}$, indicating that the ligand expands in the plane perpendicular to the $C_{3}$ axis in order to accommodate the $\mathrm{K}^{+}$cation. The TACN centroidcentroid distances reveal that this expansion is accompanied by a slight compression along the $C_{3}$ axis compared to the free ligand $\left[\mathrm{H}_{2} \cdot \mathbf{1}\right]^{+} \cdot 2 \mathrm{Br}^{-}$, but the degree of compression is smaller than that observed in the structure of the sodium complex $[\mathrm{Na} \cdot \mathbf{1}]^{+\cdot} \mathrm{Cl}^{-}$, which may indicate that the presence of the $\mathrm{K}^{+}$cation imposes some conformational strain on the ligand.
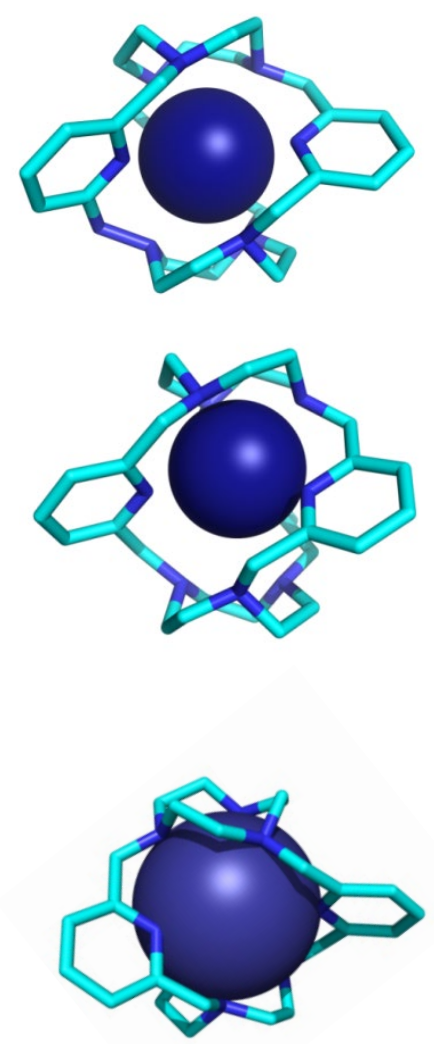

Figure 4. Orthogonal views of the contents the solid state structures of the sodium cryptate structures $[\mathrm{Na} \cdot \mathbf{1}]^{+} \cdot \mathrm{Cl}^{-}($top $)$and $[\mathrm{Na} \cdot \mathrm{H} \cdot \mathbf{1}]^{2+} \cdot 2 \mathrm{Cl}^{-}(\mathrm{middle})$ and $[\mathrm{K} \cdot \mathbf{1}]^{+} \cdot \mathrm{Cl}^{-}$ (bottom). For clarity, solvent molecules, counteranions and hydrogen atoms and have been omitted, and only one of the two independent complexes found within the asymmetric units for the $[\mathrm{Na} \cdot \mathbf{1}]^{+} \cdot \mathrm{Cl}^{-}$and $[\mathrm{K} \cdot \mathbf{1}]^{+} \cdot \mathrm{Cl}^{-}$structures are shown. 

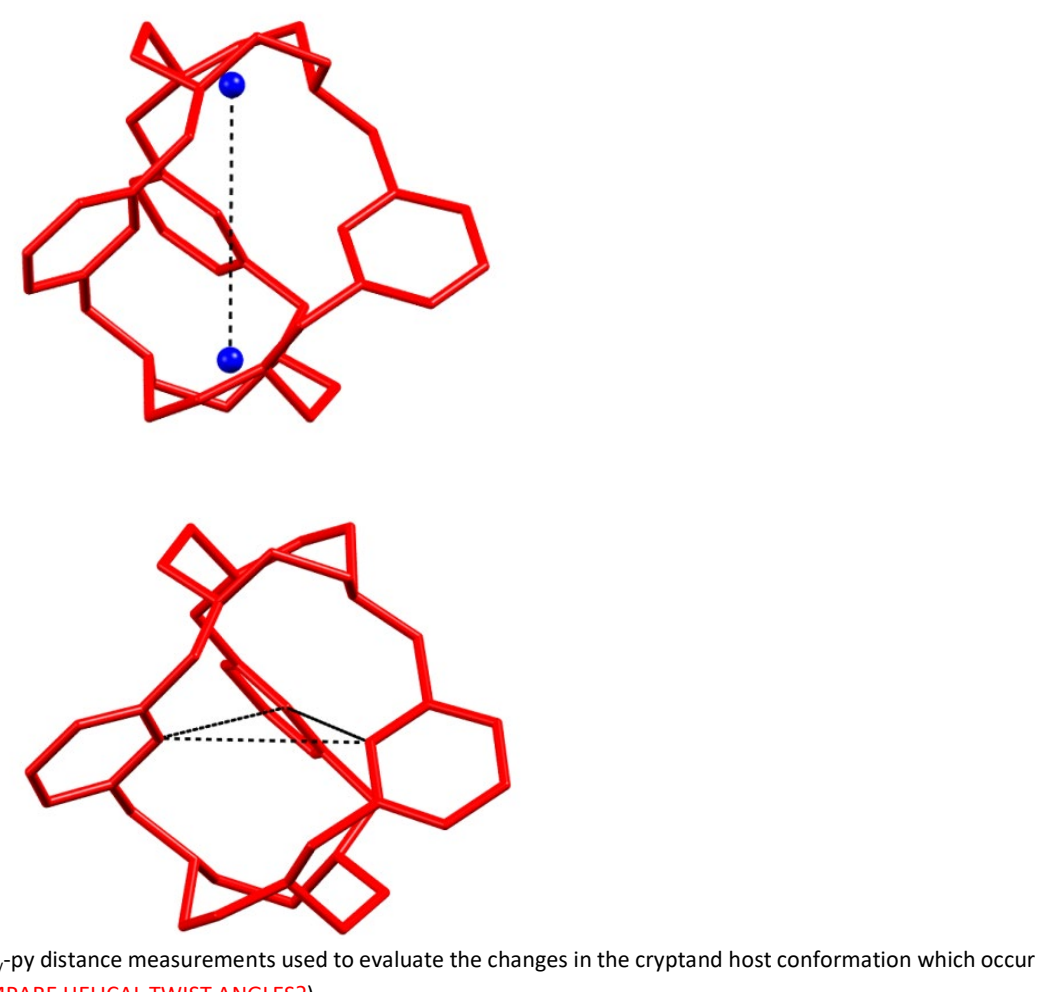

upon cation complexation. (ALSO MEASURE AND COMPARE HELICAL TWIST ANGLES?) 
Table 1. $\mathrm{M}-\mathrm{N}$ bond distances, TACN centroid-centroid distances, $\mathrm{N}_{\mathrm{py}}-\mathrm{N}_{\mathrm{py}}$ distances and NCCN torsion angles from the solid state structures of the proton and metal cryptate complexes $\left[\mathrm{H}_{2} \cdot \mathbf{1}\right]^{2+} \cdot 2 \mathrm{Br},[\mathrm{K} \cdot \mathbf{1}]^{+} \cdot \mathrm{PF}_{6}{ }^{-},[\mathrm{Na} \cdot \mathbf{1}]^{+} \cdot \mathrm{Cl}^{-}$and $[\mathrm{Na} \cdot \mathrm{H} \cdot \mathbf{1}]^{2+} \cdot 2 \mathrm{Cl}^{-}$and $[\mathrm{Pb} \cdot \mathbf{1}]^{2+} \cdot 0.57 \mathrm{PbCl}_{4}{ }^{2-} \cdot 0.43 \mathrm{PbCl}_{3} \mathrm{AcO}^{2-}$.

\begin{tabular}{|c|c|c|c|c|c|}
\hline & {$\left[\mathrm{H}_{2} \cdot 1\right]^{+} \cdot 2 \mathrm{Br}^{-}$} & {$[\mathrm{Na} \cdot 1]^{+} \cdot \mathrm{Cl}^{-}$} & {$[\mathrm{Na} \cdot \mathrm{H} \cdot 1]^{+} \cdot \mathrm{Cl}^{-}$} & {$[\mathrm{K} \cdot 1]^{+} \cdot \mathrm{Cl}^{-}$} & {$[\mathrm{Pb} \cdot 1]^{+} \cdot \mathrm{X}^{-}$} \\
\hline $\begin{array}{c}\boldsymbol{R}\left(\mathbf{M}^{+}\right)+R_{\mathrm{vdw}}(\mathbf{N}) \\
(\AA \AA)\end{array}$ & - & 2.79 & 2.57 & 3.10 & 2.90 \\
\hline $\begin{array}{c}\mathrm{M}-\mathrm{N}_{\mathrm{py}} \text { distances } \\
(\stackrel{\mathrm{A})}{ })\end{array}$ & - & $\begin{array}{l}2.577 \\
2.578 \\
2.589 \\
2.611 \\
2.587 \\
2.597 \\
\end{array}$ & $\begin{array}{l}2.465 \\
2.550 \\
2.505\end{array}$ & $\begin{array}{l}2.753 \\
2.709 \\
2.745\end{array}$ & $\begin{array}{l}2.655 \\
2.668 \\
2.695\end{array}$ \\
\hline $\begin{array}{c}\text { M-N } \mathbf{N}_{\text {TACN }} \text { distances } \\
\left.(\AA)^{b}\right)^{b}\end{array}$ & - & $\begin{array}{l}2.840 \\
2.825 \\
2.843 \\
2.833 \\
2.859 \\
2.868 \\
2.843 \\
2.824 \\
2.857 \\
2.820 \\
2.819 \\
2.847 \\
\end{array}$ & $\begin{array}{l}2.475 \\
2.483 \\
2.476 \\
3.404 \\
3.518\end{array}$ & $\begin{array}{l}2.892 \\
2.888 \\
2.939 \\
2.871 \\
2.937 \\
2.893\end{array}$ & $\begin{array}{l}2.804 \\
2.771 \\
2.695 \\
2.776 \\
2.825 \\
2.784\end{array}$ \\
\hline $\begin{array}{l}\text { TACN centroid- } \\
\text { centroid distance } \\
(\AA)^{b}\end{array}$ & 5.209 & $\begin{array}{l}4.565 \\
4.538\end{array}$ & 4.889 & $\begin{array}{l}4.968 \\
4.644\end{array}$ & 4.486 \\
\hline $\begin{array}{c}N_{p y}-N_{p y} \text { distances } \\
\text { (A) }\end{array}$ & $\begin{array}{l}3.959 \\
4.015 \\
4.082\end{array}$ & $\begin{array}{l}4.465 \\
4.467 \\
4.481 \\
4.520 \\
4.479 \\
4.506 \\
\end{array}$ & $\begin{array}{l}4.176 \\
4.264 \\
4.223\end{array}$ & $\begin{array}{c}4.807 \\
4.84 \\
4.897 \\
4.626 \\
4.674 \\
4.708\end{array}$ & $\begin{array}{l}4.581 \\
4.597 \\
4.708\end{array}$ \\
\hline $\begin{array}{c}\text { TACN NCCN } \\
\text { torsion angles } \\
\left({ }^{\circ}\right)\end{array}$ & $\begin{array}{l}45.0 \\
47.5 \\
42.9 \\
49.0 \\
47.0 \\
46.0\end{array}$ & $\begin{array}{c}51.3 \\
50.5 \\
51.4 \\
50.9 \\
50.7 \\
49.4 \\
50.9 \\
-51.7 \\
-50.2 \\
-51.5 \\
-51.1 \\
-51.0\end{array}$ & $\begin{array}{l}49.3 \\
50.7 \\
47.9 \\
43.5 \\
45.3 \\
48.6\end{array}$ & $\begin{array}{c}\text { CHECK - USING } \\
\text { AVERAGE } \\
\text { RESTRAINTS ON } \\
\text { ANGLES AT THE } \\
\text { MOMENT }\end{array}$ & $\begin{array}{c}\text { CHECK - USING } \\
\text { AVERAGE } \\
\text { RESTRAINTS ON } \\
\text { ANGLES AT THE } \\
\text { MOMENT }\end{array}$ \\
\hline
\end{tabular}

The sum of the ionic and van der Waals radii of the metal cation and nitrogen. ${ }^{40,41}$ The values for the ionic radii are based on a coordination number of 9 for the $[\mathrm{K} \cdot \mathbf{1}]^{+} \cdot \mathrm{PF}_{6}{ }^{-},[\mathrm{Na} \cdot \mathbf{1}]^{+} \cdot \mathrm{Cl}^{-}$and $[\mathrm{Pb} \cdot 1]^{2+} \cdot 0.57 \mathrm{PbCl}_{4}{ }^{2-} \cdot 0.43 \mathrm{PbCl}_{3} \mathrm{AcO}^{2-}$ structures, and a coordination number of 6 for the $[\mathrm{Na} \cdot \mathrm{H} \cdot 1]^{2+} \cdot 2 \mathrm{Cl}^{-}$structure. ${ }^{b} \mathrm{TACN}$ centroidcentroid and $\mathrm{N}_{\mathrm{py}}-\mathrm{N}_{\mathrm{py}}$ distances are defined in Figure 5.

Lead complexation. We reasoned that the azacryptand 1 may hold potential as a complementary host for the toxic divalent lead cation based on manifold considerations: the ionic radius of the $\mathrm{Pb}$ (II) cation lies in between those of $\mathrm{Na}^{+}$and $\mathrm{K}^{+},{ }^{40}$ while $\mathrm{Pb}(\mathrm{II})$ also benefits from a higher divalent charge; the ligand's exclusive provision of nitrogen donor groups should help to confer selectivity for $\mathrm{Pb}$ (II) over harder alkali metal cations; furthermore $\mathrm{Pb}$ (II) is known to form complexes with high coordination numbers of up to 10 , and has been previously documented to bind to various azacryptand hosts ${ }^{42-46}$ as well as to macrocyclic ligands incorporating TACN ${ }^{47-50}$ and pyridy| $\left.\right|^{48,50-54}$ donor groups. In order to test the ligand's capacity for lead encapsulation the potassium cryptate complex $[\mathrm{K} \cdot \mathbf{1}]^{+} \cdot \mathrm{Cl}^{-}$was heated in the presence of a threefold excess of $\mathrm{Pb}(\mathrm{OAc})_{2}$ in $\mathrm{CH}_{3} \mathrm{CN}$. During monitoring of the reaction by electrospray mass spectrometry, the $[1+\mathrm{K}]^{+}$molecular ion $(m / z=606)$ gradually disappeared and was replaced by a new peak centred at $m / z=389$ corresponding to the $[1+\mathrm{Pb}]^{2+}$ ion, suggesting that the $\mathrm{Pb}^{2+}$ cation slowly displaces the $\mathrm{K}^{+}$cation from the cryptand's cavity, with the transmetallation reaction reaching completion within 48 hours. The lead cryptate complex $[\mathrm{Pb} \cdot 1]^{+} \cdot 2 \mathrm{AcO}^{-}$was isolated in $70 \%$ yield. The ${ }^{1} \mathrm{H}$ NMR spectrum of this lead cryptate is compared with that of the potassium cryptate in Figure 6. Significant downfield shifts in the aromatic pyridyl and methylene $\mathrm{CH}_{2}$ proton signals are observed upon displacement of $\mathrm{K}^{+}$by the divalent $\mathrm{Pb}^{2+}$ cation. In addition satellites of the methylene proton and carbon signals were observed in the ${ }^{1} \mathrm{H}$ NMR and ${ }^{13} \mathrm{C} N M R$ spectra respectively as a result of coupling to ${ }^{207} \mathrm{~Pb}(\mathrm{I}=1 / 2 ; 22 \%$ abundance). There is no apparent desymmetrisation of the spectrum upon 
complexation of $\mathrm{Pb}^{2+}$, suggesting a spherically symmetrical charge distribution around the cation, with no stereochemical activity from the $6 \mathrm{~s}^{2}$ lone electron pair, as might be expected in a nonacoordinate $\mathrm{Pb}^{2+}$ complex. $^{55}$

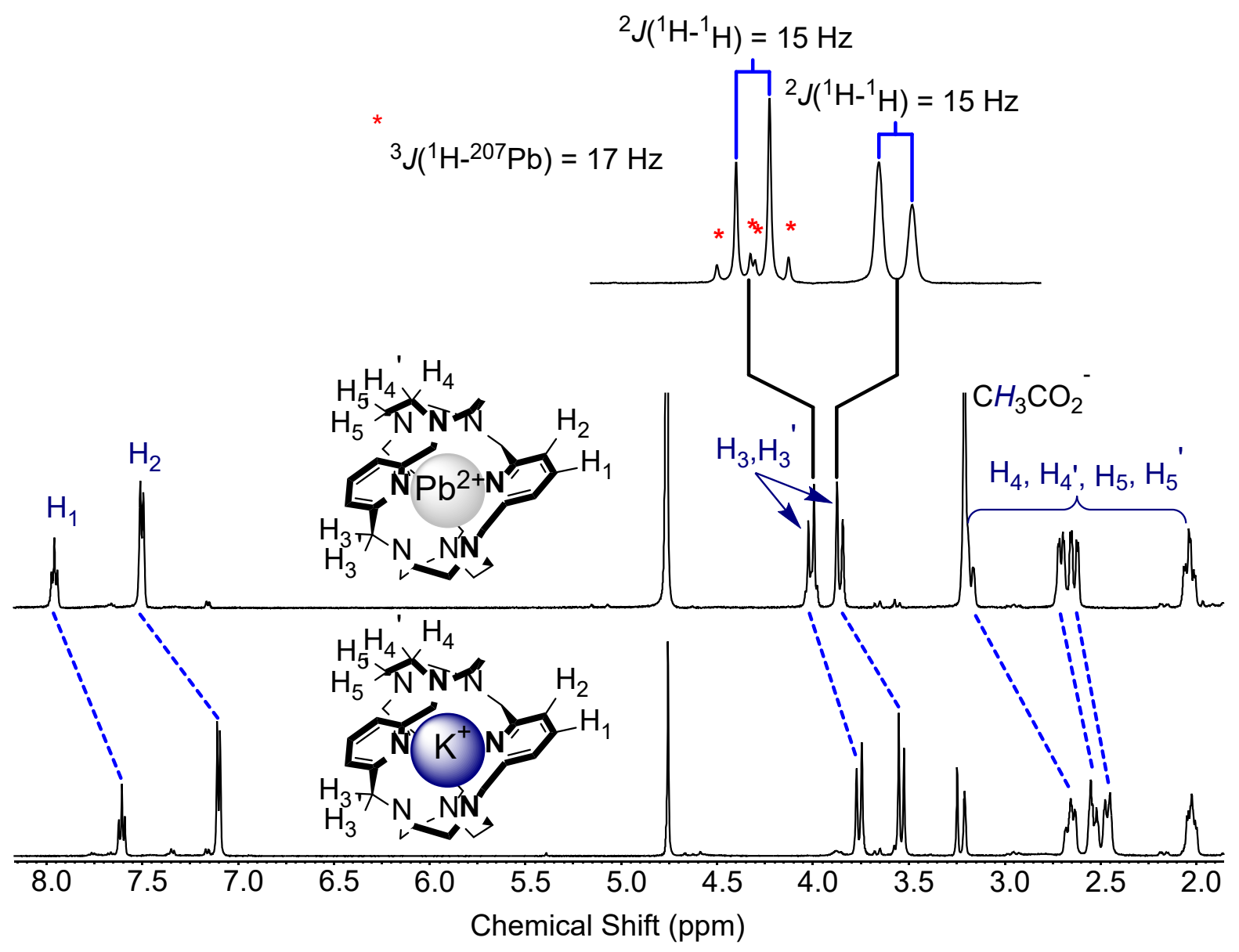

Figure 6. Comparative ${ }^{1} \mathrm{HNMR}$ spectra $\left(400 \mathrm{MHz} ; \mathrm{CD}_{3} \mathrm{OD} ; 298 \mathrm{~K}\right)$ of the lead cryptate complex $[\mathrm{Pb} \cdot \mathbf{1}]^{+} \cdot 2 \mathrm{AcO}^{-}$(top) and potassium cryptate complex $[\mathrm{K} \cdot 1]^{+} \cdot \mathrm{Cl}^{-}$ (bottom)

The lead complex was also characterised in the solid state. While a number of lead cryptate complexes have previously been structurally characterised, $42,45,46,56,57$ to the best of our knowledge this is the first example of a nonacoordinate $\mathrm{Pb}(\mathrm{II}) \mathrm{N}_{9}$ azacryptand complex. After repeated unsuccessful attempts to obtain X-ray quality crystals of the complex $[\mathrm{Pb} \cdot \mathbf{1}]^{+} \cdot 2 \mathrm{AcO}^{-}$, single crystals were grown from a sample of the chloride salt $[\mathrm{Pb} \cdot \mathbf{1}]^{+} \cdot 2 \mathrm{Cl}^{-}$, which was prepared by anion exchange of the acetate salt $[\mathrm{Pb} \cdot 1]^{+} \cdot 2 \mathrm{AcO}^{-}$using Amberlite IRA400 ion exchange resin. However, upon solving the structure the lead cryptate complex was found to have crystallised with the unexpected complex counteranions $\mathrm{PbCl}_{4}{ }^{2-}$ and $\mathrm{PbCl}_{3} \mathrm{AcO}^{2-}$ which occupy the same crystallographic site with fractional occupancies of 0.57 and 0.43 respectively. The cryptate structure reveals a symmetrically located $\mathrm{Pb}$ (II) cation which is co-planar with the three pyridyl nitrogen donors and co-linear with the two TACN centroids $\left(\angle\right.$ centroid- $\mathrm{Pb}^{2+}-$ centroid: $\left.178.7^{\circ}\right)$, indicating a holodirected geometry with no evidence of any stereochemical lone pair activity. The $\mathrm{Pb}-\mathrm{N}_{\mathrm{py}}(2.664-2.707 \AA$; mean $=2.680 \AA)$ and $\mathrm{Pb}-\mathrm{N}_{\mathrm{TACN}}$ distances $(2.773-2.828 \AA$; mean $=2.800 \AA$ ) are $3-8 \%$ shorter than the sum of the ionic and van der Waals radii of nonacoordinate divalent lead and nitrogen $(2.90 \AA \AA) .40,41$ The TACN centroid-to-centroid distance $(4.486 \AA)$ is the shortest of those observed in any of the five cryptate structures discussed here while the $N_{p y}-N_{p y}$ distances $(4.586-4.711 \AA ̊$; mean $=4.641 \AA$ ) lie in between those observed in the structures of the sodium and potassium cryptates. 

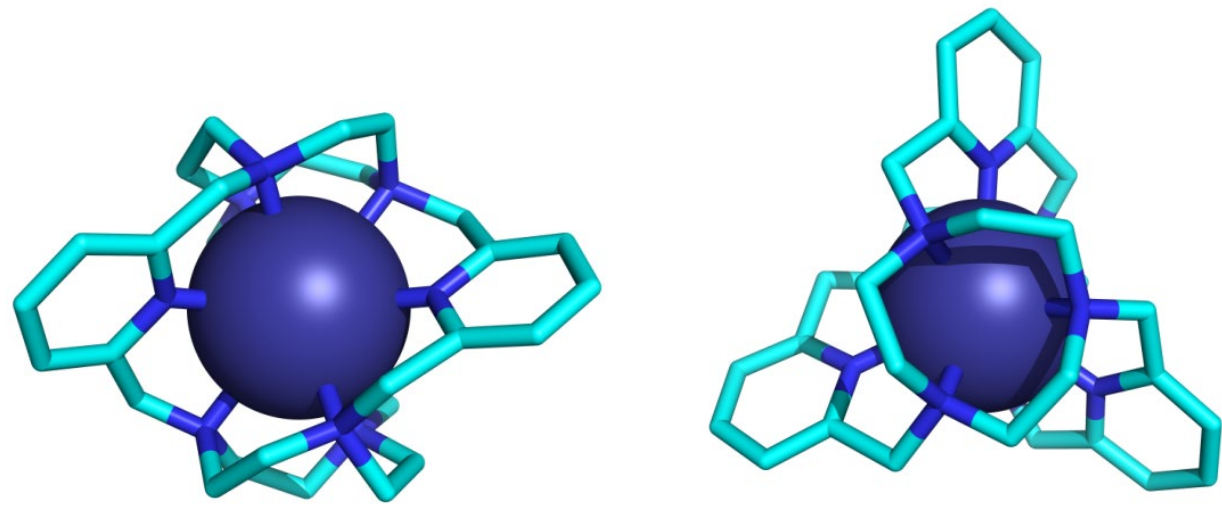

Figure 7. Orthogonal views of the solid state structure of the lead cryptate complex $[\mathrm{Pb} \cdot 1]^{2+} \cdot 0.57 \mathrm{PbCl}_{4}{ }^{2-} \cdot 0.43 \mathrm{PbCl}_{3} \mathrm{AcO}^{2-}$. For clarity, solvent molecules, counteranions and hydrogen atoms and have been omitted.

Competition experiments. In order to obtain a qualitative estimate of the selectivity of the cryptand $\mathbf{1}$ for $\mathrm{Pb}$ (II) over other cations we employed a series of competition experiments. $\mathrm{Na}^{+}, \mathrm{K}^{+}, \mathrm{Zn}^{2+}$ and $\mathrm{Ca}^{2+} \mathrm{Cations}^{2}$ were identified as potentially important competitors whose concentrations may typically exceed those of $\mathrm{Pb}$ (II) during environmental and biomedical applications of $\mathrm{Pb}(\mathrm{II})$ chelation processes. Initially a $\mathrm{CH}_{3} \mathrm{CN}$ solution of the potassium complex $[\mathrm{K} \cdot \mathbf{1}]^{+} \cdot \mathrm{Cl}^{-}$was heated at reflux in the presence of 3 molar equivalents of $\mathrm{Pb}(\mathrm{OAc})_{2}, \mathrm{Ca}\left(\mathrm{ClO}_{4}\right)_{2}, \mathrm{Zn}\left(\mathrm{ClO}_{4}\right)_{2}$ and $\mathrm{NaCl}$. After four days analysis of the mixture by electrospray mass spectrometry indicated that only the $\mathrm{Na}^{+}$and $\mathrm{Pb}$ (II) cryptate complexes were present (Figure 8). A $1 \mathrm{mM}$ solution of the free cryptand ligand 1 in $\mathrm{MeOH}$ was then heated in the presence of equimolar quantities of $\mathrm{NaCl}, \mathrm{KCl}, \mathrm{ZnCl}_{2}, \mathrm{CaCl}_{2}$ and $\mathrm{Pb}(\mathrm{OAc})_{2}$. Analysis of the product distribution by electrospray mass spectrometry and ${ }^{1} \mathrm{H}$ NMR spectroscopy again indicated preferential formation of the sodium and lead cryptate complexes from this multicomponent mixture, with no evidence of the formation of the potassium, calcium or zinc complexes. From the ${ }^{1} \mathrm{H}$ NMR integral ratios it the sodium and lead complexes were estimated to have formed in an approximate 2:1 molar ratio. When this experiment was repeated using the alternative metal salts $\mathrm{Pb}(\mathrm{OAc})_{2}, \mathrm{NaOTf}, \mathrm{KPF}_{6}, \mathrm{Ca}\left(\mathrm{ClO}_{4}\right)_{2}$ and $\mathrm{Zn}\left(\mathrm{ClO}_{4}\right)_{2}$ an altered 1:3 stoichiometric ratio of the sodium and lead cryptate complexes was observed. The higher ratio of formation of the lead complex in the absence of chloride counteranions may reflect reduced competition from precipitation of insoluble $\mathrm{PbCl}_{2}$. The $\mathrm{cryptand}$ therefore appears to show a reproducible selectivity for complexation of $\mathrm{Na}^{+}$and $\mathrm{Pb}^{2+}$ cations in the presence of a range of other cations and counteranions.

Very difficult to be certain that the 'free ligand' was not already bound to something, or what protonation state it was in. Going to repeat using potassium complex, one molar equivalent of each cation salt and try to find salts with more consistent counteranions. Also tried lead $\mathrm{CH}_{2} \mathrm{Cl}_{2} / \mathrm{H}_{2} \mathrm{O}$ extraction experiment but failed to extract anything. Although the alkali metal complexes have good solubilities in organic solvents the lead complex is much less soluble, which probably doesn't help. 


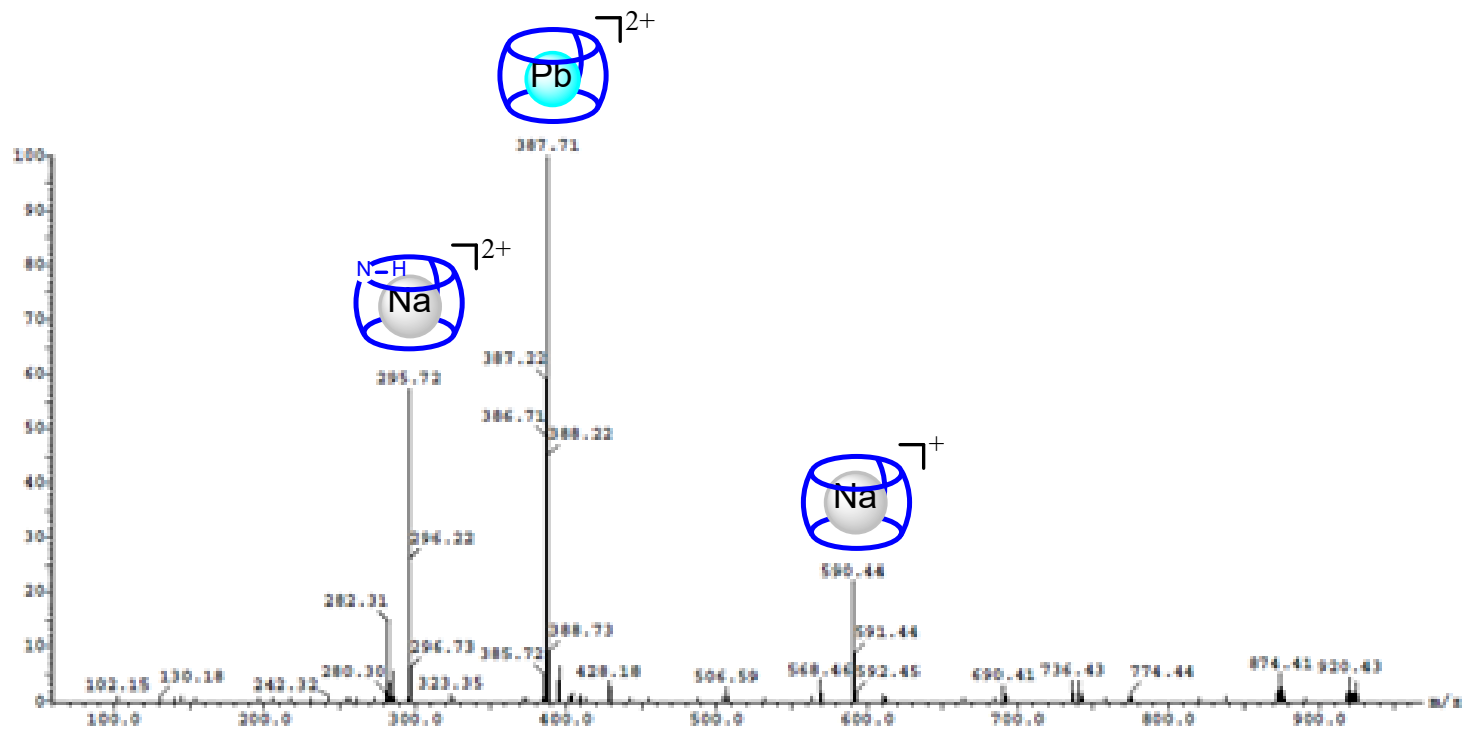

Figure 8. Electrospray mass spectrum of the product mixture obtained after exposure of the potassium cryptate complex to a mixture of $\mathrm{Na}^{+}, \mathrm{Ca}^{2+}, \mathrm{Zn}(\mathrm{II})$ and $\mathrm{Pb}(\mathrm{II})$ cations in refluxing acetonitrile.

\section{Conclusions}

A new $N_{9}$ azacryptand 'Beer can' ligand was synthesised via a convenient one-pot [2+3] condensation reaction which is thought to be templated by sodium and potassium cations. The diprotonated free ligand $\left[\mathrm{H}_{2} \cdot \mathbf{1}\right]^{+} \cdot 2 \mathrm{Br}^{-}$and the metal cryptate complexes $[\mathrm{K} \cdot \mathbf{1}]^{+} \cdot \mathrm{X}^{-},[\mathrm{Na} \cdot \mathbf{1}]^{+} \cdot \mathrm{Cl}^{-}$and $[\mathrm{Na} \cdot \mathrm{H} \cdot \mathbf{1}]^{+} \cdot 2 \mathrm{Cl}^{-}$and $[\mathrm{Pb} \cdot \mathbf{1}]^{+} \cdot 2 \mathrm{X}^{-}$were structurally characterised in the solid state. The structures demonstrate that the highly preorganised cage-like ligand is capable of undergoing slight conformational distortions in order to optimally accommodate each cation. Preliminary cation binding competition experiments revealed that the new cryptand exclusively binds sodium and lead in the presence of potassium, zinc and calcium cations. Detailed quantitative investigations into the thermodynamic and kinetic aspects of the cryptand's metal cation binding properties are continuing in our laboratories.

\section{Notes and references}

\# When the cryptand forming reaction was carried out in the presence of $\mathrm{Li}_{2} \mathrm{CO}_{3}$, analysis of the crude product distribution suggested formation of an analogous mixture of the two cryptate complexes $\left[\mathrm{Li}^{\prime} \cdot \mathbf{1}\right]^{+} \cdot \mathrm{X}^{-}$and $[\mathrm{Li} \cdot \mathrm{H} \cdot \mathbf{1}]^{2+} \cdot 2 \mathrm{X}^{-}$. However, this mixture proved impossible to separate using alumina chromatography and the two products could not therefore be individually characterised. Upon crystallisation of the crude product mixture we obtained a preliminary solid state structure of the $[\mathrm{Li} \cdot \mathrm{H} \cdot \mathbf{1}]^{2+} \cdot 2 \mathrm{X}^{-}$in which the lithium cation displays a six-coordinate geometry, similar to that of the sodium cation in the $[\mathrm{Na} \cdot \mathrm{H} \cdot \mathbf{1}]^{2+} \cdot 2 \mathrm{Cl}^{-}$structure discussed above; however, owing to the extremely low quality of the data we have not included this structure for discussion.

$\S$ The hexafluophosphate salt of the the potassium cryptate complex was prepared by treatment of the chloride salt, $[\mathrm{K} \cdot \mathbf{1}]^{+} \mathrm{Cl}^{-}$with $\mathrm{KPF}_{6}$

I The diprotonated free ligand $\left[\mathrm{H}_{2} \cdot \mathbf{1}\right]^{2+} \cdot 2 \mathrm{Br}^{-}$was isolated during an attempted purification of the potassium cryptate by preparative thin layer chromatography on silica using a $\mathrm{CH}_{2} \mathrm{Cl}_{2} / \mathrm{MeOH} / \mathrm{NH}_{4} \mathrm{OH}_{(\mathrm{aq})}$ eluent system. As this was one of several minor products which were isolated in very small quantity it was characterised only in the sold state.

$1 \quad$ J. M. Lehn, Acc. Chem. Res., 1978, 11, 49-57.

$2 \quad$ B. Dietrich, J. M. Lehn and J. P. Sauvage, Tetrahedron Lett., 1969, 10, 2889-2892.

3 B. Dietrich, J. M. Lehn and J. P. Sauvage, Tetrahedron, 1973, 29, 1647-1658.

$4 \quad$ B. Dietrich, J. M. Lehn and J. P. Sauvage, Tetrahedron Lett., 1969, 10, 2885-2888.

5 B. Dietrich, J. M. Lehn, J. P. Sauvage and J. Blanzat, Tetrahedron, 1973, 29, 1629-1645.

6 D. Moras, B. Metz and R. Weiss, Acta Crystallogr. B, 1973, 29, 383-388.

7 J. M. Lehn and J. P. Sauvage, J Chem Soc D, 1971, 0, 440-441.

8 J. M. Lehn and J. P. Sauvage, J. Am. Chem. Soc., 1975, 97, 6700-6707.

9 C. Moore and B. C. Pressman, Biochem. Biophys. Res. Commun., 1964, 15, 562-567.

10 J. M. Lehn, J. P. Sauvage and B. Dietrich, J. Am. Chem. Soc., 1970, 92, 2916-2918.

11 A. E. Martell, R. D. Hancock and R. J. Motekaitis, Coord. Chem. Rev., 1994, 133, 39-65.

12 X. X. Zhang, R. M. Izatt, J. S. Bradshaw and K. E. Krakowiak, Coord. Chem. Rev., 1998, 174, 179-189.

13 P. Auffinger and G. Wipff, J. Am. Chem. Soc., 1991, 113, 5976-5988.

14 G. Wipff, J. Coord. Chem., 1992, 27, 7-37. 
E. S. Leite, S. R. Santana, P. H. Hünenberger, L. C. G. Freitas and R. L. Longo, J. Mol. Model., 2007, 13, 1017-1025. V. McKee, J. Nelson and R. M. Town, Chem. Soc. Rev., 2003, 32, 309-325.

S. O. Kang, J. M. Llinares, V. W. Day and K. Bowman-James, Chem. Soc. Rev., 2010, 39, 3980.

Y. Han, Y. Jiang and C.-F. Chen, Tetrahedron, 2015, 71, 503-522.

D. Landini, A. Maia, F. Montanari and P. Tundo, J. Am. Chem. Soc., 1979, 101, 2526-2530.

A. Woodruff, C. A. Pohl, A. Bordunov and N. Avdalovic, J. Chromatogr. A, 2002, 956, 35-41.

M.-T. Lai and J.-S. Shih, The Analyst, 1986, 111, 891.

S. K. Srivastava, V. K. Gupta and S. Jain, Anal. Chem., 1996, 68, 1272-1275.

M. K. Amini, M. Mazloum and A. A. Ensafi, Fresenius J. Anal. Chem., 1999, 364, 690-693.

F. J. Tehan, B. L. Barnett and J. L. Dye, J. Am. Chem. Soc., 1974, 96, 7203-7208.

J. Kim, A. S. Ichimura, R. H. Huang, M. Redko, R. C. Phillips, J. E. Jackson and J. L. Dye, J. Am. Chem. Soc., 1999, 121, 10666-10667.

R. H. Huang, M. K. Faber, K. J. Moeggenborg, D. L. Ward and J. L. Dye, Nature, 1988, 331, $599-601$.

P. A. Edwards and J. D. Corbett, Inorg. Chem., 1977, 16, 903-907.

J. M. Goicoechea and S. C. Sevov, J. Am. Chem. Soc., 2004, 126, 6860-6861.

C. Suchentrunk and N. Korber, New J. Chem., 2006, 30, 1737-1739.

C.-J. Chuang, W.-S. Li, C.-C. Lai, Y.-H. Liu, S.-M. Peng, I. Chao and S.-H. Chiu, Org. Lett., 2009, 11, 385-388.

H. Sigel*, Coord. Chem. Rev., 2001, 219-221, 435-461.

J. S. Magyar, T.-C. Weng, C. M. Stern, D. F. Dye, B. W. Rous, J. C. Payne, B. M. Bridgewater, A. Mijovilovich, G. Parkin, J. M. Zaleski, J. E. Penner-Hahn and H. A. Godwin, J. Am. Chem. Soc., 2005, 127, 9495-9505.

E. K. Jaffe, J. Martins, J. Li, J. Kervinen and R. L. Dunbrack, J. Biol. Chem., 2001, 276, 1531-1537.

H. Needleman, Annu. Rev. Med., 2004, 55, 209-222.

E. Rossi, Clin. Biochem. Rev., 2008, 29, 63-70.

M. Guziński, G. Lisak, J. Kupis, A. Jasiński and M. Bocheńska, Anal. Chim. Acta, 2013, 791, 1-12.

S. J. S. Flora and V. Pachauri, Int. J. Environ. Res. Public. Health, 2010, 7, 2745-2788.

J. Cheney and J. M. Lehn, J. Chem. Soc., Chem. Commun., 1972, 487-489.

R. Pizer, J. Am. Chem. Soc., 1978, 100, 4239-4241.

R. D. Shannon, Acta Crystallogr. Sect. A, 1976, 32, 751-767.

A. Bondi, J. Phys. Chem., 1964, 68, 441-451.

B. Metz and R. Weiss, Inorg. Chem., 1974, 13, 2094-2098.

S. Shinkai, T. Kouno, Y. Kusano and O. Manabe, J Chem Soc Perkin Trans 1, 1982, 2741-2747.

H.-J. Buschmann, Inorganica Chim. Acta, 1985, 98, 43-46.

N. Martin, V. McKee and J. Nelson, Inorganica Chim. Acta, 1994, 218, 5-8.

D. Esteban-Gómez, T. Enríquez-Pérez, R. Ferreirós-Martínez, M. Mato-Iglesias, C. Platas-Iglesias, A. de Blas and T. Rodríguez-Blas, Eur. J. Inorg. Chem., 2010, 2010, 5027-5034.

M. Di Vaira, M. Guerra, F. Mani and P. Stoppioni, J. Chem. Soc. Dalton Trans., 1996, 1173.

C. Bazzicalupi, A. Bencini, E. Faggi, A. Garau, C. Giorgi, V. Lippolis, A. Perra and B. Valtancoli, Dalton Trans, 2006, 1409-1418.

M. Mameli, M. C. Aragoni, M. Arca, M. Atzori, A. Bencini, C. Bazzicalupi, A. J. Blake, C. Caltagirone, F. A. Devillanova, A. Garau, M. B. Hursthouse, F. Isaia, V. Lippolis and B. Valtancoli, Inorg. Chem., 2009, 48, 9236-9249. D. Over, X. Zeng, C. Bornholdt, J. Marrot and O. Reinaud, Inorg. Chem., 2013, 52, 14089-14095. A. J. Blake, A. Bencini, C. Caltagirone, G. De Filippo, L. S. Dolci, A. Garau, F. Isaia, V. Lippolis, P. Mariani, L. Prodi, M. Montalti, N. Zaccheroni and C. Wilson, Dalton Trans, 2004, 2771-2779.

A. Freiría, R. Bastida, L. Valencia, A. Macías, C. Lodeiro and H. Adams, Inorganica Chim. Acta, 2006, 359, 23832394.

R. Ferreirós-Martínez, D. Esteban-Gómez, É. Tóth, A. de Blas, C. Platas-Iglesias and T. Rodríguez-Blas, Inorg. Chem., 2011, 50, 3772-3784.

J. Gregoliński, K. Ślepokura and J. Lisowski, Dalton Trans, 2015, 44, 16345-16351.

L. Shimoni-Livny, J. P. Glusker and C. W. Bock, Inorg. Chem., 1998, 37, 1853-1867.

A. N. Chekhlov, Russ. J. Inorg. Chem., 2006, 51, 235-240.

A. N. Chekhlov, Russ. J. Coord. Chem., 2006, 32, 552-558. 